\title{
Peras con manzanas: comparación entre los objetivos constitucionales del acceso a la propiedad rural y la implementación de programas de formalización ${ }^{*}$
}

\author{
Apples and Oranges: Comparison between the Rural Land \\ Access Goals Set by the Constitution and Land Titling Programs \\ Peras com maçãs: comparação entre os objetivos constitucionais \\ de acesso à propriedade rural e a implementação \\ de programas de formalização
}

\author{
BRYAN TRIANA ANCINEZ ${ }^{* *}$ \\ Milton Alberto Valencia Herrera ${ }^{* *}$ \\ ALFONSO JAVIER LOZANO VALCÁRCEL ${ }^{\star \star \star \star}$ \\ Nusmem Alfredo Acosta Agullar ${ }^{* \star \star \star \star}$
}

FeCha de ReCepción: 31 de Agosto de 2020. FeCha de AProbación: 25 de octubre de 2020

Doi: https://doi.org/10.12804/revistas.urosario.edu.co/sociojuridicos/a.9598

Para citar este artículo: Triana Ancinez, B., Valencia Herrera, M. A., Lozano Valcárcel, A. J., E Acosta Aguilar, N. A. (2021). Peras con manzanas: comparación entre los objetivos constitucionales del acceso a la propiedad rural y la implementación de programas de formalización. Revista de Estudios Socio-Jurídicos, 23(1), 35-69. https:doi. org/10.12804/revistas.urosario.edu.co/sociojuridicos/a.9598

* Este artículo es resultado del proyecto de investigación Cultivos de uso ilícito y formalización de los derechos de propiedad de la tierra: una evaluación de las políticas públicas para una paz estable y duradera financiado por el Ministerio de Ciencia, Tecnología e Innovación. Queremos expresar nuestra gratitud a todo el equipo del Observatorio de Restitución y Regulación de Derechos de Propiedad Agraria (ORRDPA) con quienes hemos podido debatir algunas de las ideas aquí expuestas.

** Investigador del ORRDPA. Correo electrónico: britian92@gmail.edu.co

*** Investigador del ORRDPA. Correo electrónico: milton.valenciah@gmail.com

**** Investigador del ORRDPA. Correo electrónico: ponchispsn@gmail.com

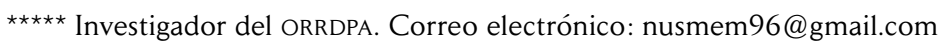




\title{
RESUMEN
}

El presente artículo busca mostrar los alcances y limitaciones de los programas de formalización como políticas para cumplir los objetivos sobre acceso a tierras que fueron debatidos y aprobados en la Asamblea Nacional Constituyente (ANC). Para ello, se ofrece una conceptualización jurídica de la formalización y se describen los programas que hacen uso de este mecanismo. Luego, se describen los debates que se realizaron en la ANC y se enuncian los fines que aspiraba cumplir el constituyente al establecer el deber del Estado de promover el acceso a la propiedad rural. Finalmente, se argumenta que la formalización no cumple con lo establecido en el artículo 64 de la Constitución Política al comparar los mecanismos de formalización con el texto constitucional y con los resultados de un sondeo realizado en zonas donde se implementaron estas políticas. Como conclusión, encontramos que los programas de formalización no son necesarios ni suficientes para desarrollar las aspiraciones constitucionales relativas al acceso a la propiedad rural.

Palabras clave: formalización; derecho agrario; acceso a tierras; campesinos; derecho constitucional.

\begin{abstract}
The following paper aims at showing the reach and shortcomings of formalization programs as means to fulfil the objectives traced by the Asamblea Nacional Constituyente (ANC) in terms of land redistribution. For that purpose, we explain land titling operations in Colombia and describe their programs. Then, we describe the relevant debates of the ANC and present the goals traced for the State regarding land redistribution. Finally, we argue that land titling does not fulfill the mandates of the Constitution by comparing these programs with the Constitution and the results from a poll of the areas where these programs were implemented. We found that land titling programs are neither necessary nor sufficient to fulfill the Constitutional mandates.
\end{abstract}

Keywords: Land titling; agrarian law; access to land; peasant; constitutional law.

\section{RESUMO}

O presente artigo busca mostrar o alcance e as limitações dos programas de formalização como políticas para cumprir com os objetivos de acesso à terra que foram debatidos e aprovados na Assembleia Nacional Constituinte (ANC). Para isso, realizou-se uma contextualização jurídica da formalização e os programas que fazem uso desse mecanismo foram descritos. Em seguida, descrevem-se os debates ocorridos na ANC e expõem-se os objetivos que o constituinte almejava cumprir ao instituir o dever do Estado de promover o acesso à propriedade rural. Por fim, argumenta-se que a formalização não obedece ao disposto no artigo 64 da Constituição Política ao se comparar os mecanismos de formalização com o texto constitucional e com os resultados de uma pesquisa realizada nas áreas onde essas políticas foram implementadas. Como conclusão, descobrimos que os programas de formalização não são necessários nem suficientes para desenvolver aspirações constitucionais em relação ao acesso à propriedade rural.

Palavras-chave: formalização; direito agrário; acesso à terra; camponeses; direito constitucional. 


\section{Introducción}

En la década de 1930, las dinámicas políticas y sociales forzaron a que en Colombia se crearan estrategias para dotar de tierras a la población del sector rural (Machado, 2009). Para ello, se diseñaron programas con el objeto de entregar predios baldíos o redistribuir la propiedad privada agraria en el país, aunque ninguno se ejecutó completamente ni cumplió cabalmente su finalidad (Centro Nacional de Memoria Histórica, 2013). El primer intento se presentó con la Ley 200 de 1936. Con esta norma se pretendió brindar garantías jurídicas a los colonos sobre las nuevas tierras baldías que trabajaban. Sin embargo, la legislación terminó fortaleciendo la privatización de las tierras por personas que tenían grandes extensiones y generó la expulsión de los colonos (Berry, 2002).

El segundo intento de reforma agraria se implementó a través de la Ley 135 de 1961. En esta se crearon mecanismos para redistribuir la propiedad mediante el establecimiento de herramientas que permitían adquirir tierra privada (compra directa, expropiación o extinción de dominio) para luego entregarla a los campesinos (Centro Nacional de Memoria Histórica, 2016). Además, en materia de titulación de baldíos se creó el Incora para administrar y entregar estos bienes, y se establecieron límites para su adjudicación como la imposibilidad de adjudicar predios ocupados por indígenas o los límites al tamaño del predio adjudicado por familia (Centro Nacional de Memoria Histórica, 2016). Aunque fueron varios los elementos destacados de esta reforma, su diseño e innovaciones fueron breves debido a la contrarreforma que se impulsó en el pacto de Chicoral, que concluyó con la modificación de varios de los aspectos establecidos inicialmente (Villamil, 2015).

En el proceso constituyente de 1991 se elevó a rango constitucional el deber del Estado de brindar acceso a tierras a la población campesina. Sobre los efectos que tuvo la Constitución de 1991 en la política agraria hay dos lecturas. La primera afirma que el texto constitucional no generó cambios significativos sobre la propiedad agraria, pues se mantuvo el régimen de propiedad individual existente (Peña et al., 2014; Sánchez, 2017). Sin embargo, esta interpretación se realizó al analizar únicamente el texto constitucional. Por el contrario, la segunda lectura 
considera que la Constitución estableció unos parámetros claros sobre la obligación de promover el acceso a tierras a través de la redistribución (Güiza et al., 2020). Güiza et al. (2020) llegan a esta conclusión al interpretar la Constitución a través de los debates de la Asamblea Nacional Constituyente (ANC).

Independientemente de la interpretación que se escoja sobre los efectos de la Constitución en la política agraria, es claro que existe un deber de promover el acceso a tierras, desarrollado principalmente por la Ley 160 de 1994 y el Decreto Ley 902 de 2017. Mediante estas normas, se impulsó un proceso de dotación de tierras en el que se dio prioridad a los mecanismos de mercado (Berry, 2002), a través del Subsidio Integral de Reforma Agraria, conservando la adjudicación de baldíos y la entrega de tierras adquiridas por el Fondo Nacional de Tierras para ser tituladas a favor de los sujetos de reforma agraria (Sanchéz, 2017).

Adicionalmente, como se mostrará en este artículo, para cumplir con la obligación del artículo constitucional 64, el Estado implementó los programas de formalización de tierras (Abril-Bonilla et al., 2019). De acuerdo con la interpretación que diferentes gobiernos han realizado de la obligación constitucional de promover el acceso a tierras, las políticas de titulación son instrumentos idóneos para cumplir con este deber (Resolución 452 de 2010, Agencia Nacional de Tierras \& Oficina de Naciones Unidas contra la Droga y el Delito en Colombia, 2018b).

Estas políticas consisten en brindar asistencia estatal a los ciudadanos con derechos precarios e incompletos sobre sus predios, con el objetivo de adelantar los procedimientos necesarios para consolidar el derecho de dominio. La llegada de este tipo de programas al país se dio en los años noventa (Abril-Bonilla et al., 2020; Acero \& Parada, 2019; Neva Diaz, 2014), con la adopción de teorías desarrolladas en los años sesenta y setenta sobre los derechos de propiedad auspiciadas por organizaciones internacionales económicas como el Banco Interamericano de Desarrollo (BID) y el Banco Mundial (Acero \& Parada, 2019; Abril-Bonilla et al., 2019).

La premisa que impulsó estos programas fue que a mayor seguridad en los derechos de propiedad, mayor sería el desarrollo (de Soto, 2000). Una parte de la literatura sobre este tipo de programas ha identificado los beneficios que se obtienen con la consolidación de los derechos de 
propiedad: acceso al sistema financiero, mejora de los bienes públicos, mayor inversión y asistencia estatal (de Soto, 2000), mientras que otros sectores señalan que la formalización por sí sola es insuficiente para obtener esos beneficios en ciertos contextos (Acero \& Parada, 2019).

Respecto de la primera parte de la literatura, De Soto (2000) planteó que los países con bajos índices de formalidad o legalidad en los derechos de propiedad tienen un grado bajo de desarrollo económico porque su población no puede disponer de la propiedad como un activo económico en los sistemas financieros o comercializarla, pues la condición de informalidad impide negociarla abiertamente en el mercado. Igualmente, se planteó que la inseguridad en los derechos de propiedad genera una baja inversión productiva, pues existe incertidumbre sobre la posibilidad de recuperar la inversión ante una eventual pérdida de la propiedad o la imposibilidad de acceder a los sistemas crediticios (Besley, 1995). Por lo anterior, se concluyó que contar con derechos de propiedad consolidados impulsa el desarrollo económico y humano, facilita la inversión estatal de bienes y servicios, permite el libre acceso al mercado y los sistemas financieros y, en general, impulsa la economía y reduce la pobreza (Bruce, 2006).

En contraposición, otros estudios muestran que, confrontando estas teorías con evidencia empírica y utilizando técnicas econométricas desarrolladas desde los años noventa, los beneficios pregonados no se han probado (Acero \& Parada, 2019) o tienen efectos diferenciales en las zonas en que se desarrollan porque es una fórmula que depende de los contextos en que se aplique (Ubink, 2009). A pesar de esta reevaluación, los programas de formalización de tierras siguen enfocándose en la importancia de consolidar derechos de propiedad por encima de otras consideraciones sobre la tenencia de la tierra (Neva Diaz, 2014).

Lo anterior, muestra que en la literatura nacional no se ha realizado una evaluación sobre las virtudes o deficiencias de los programas de formalización como política pública diseñada para cumplir con el mandato del artículo 64 de la Constitución. En este marco, el presente artículo busca llenar este vació mostrando los alcances y limitaciones de los programas de formalización como políticas para cumplir con los objetivos constitucionales sobre acceso a tierras que fueron debatidos y aprobados en la ANC. Para ello, en primer lugar, presentamos la 
definición jurídica de la formalización, explicamos sus posibles rutas o mecanismos de consolidación, describimos brevemente las políticas públicas que hemos identificado a nivel nacional y mostramos la relación que encuentra el Estado entre estos programas y la obligación de promover el acceso a la propiedad del artículo 64 de la Constitución. A continuación, reconstruimos los debates políticos al interior de la ANC relacionados con el sector agrario y el acceso a la propiedad rural para los campesinos que condujeron a consagrar constitucionalmente el acceso a tierras como una obligación del Estado y señalamos los objetivos del constituyente en esta materia.

Por último, mostramos que los programas de formalización no son aptos para cumplir con el mandato constitucional de acceso a tierras ni con los objetivos trazados en la ANC. Para ello, argumentamos que la forma en que operan los programas de formalización no permite cumplir con esos fines. Además, utilizando los resultados de un sondeo realizado a usuarios de estas políticas, analizamos el cumplimiento de los fines constitucionales de acceso a bienes públicos, crédito, asistencia técnica y comercialización de productos mediante las políticas de formalización ejecutadas en Colombia.

Como conclusión encontramos que, como el adagio popular lo menciona, estamos comparando peras con manzanas, porque los programas de formalización son políticas inadecuadas para cumplir con el fin constitucional de garantizar el acceso a la propiedad rural establecido por la ANC. Además, los objetivos que podrían cumplir no han sido satisfechos por la forma en que se han ejecutado los programas. Somos conscientes de que el acceso a tierras y las políticas de formalización no deberían compararse, pero este análisis es necesario debido a que el Estado colombiano insiste en esta relación. Esperamos contribuir al debate sobre la implementación de políticas orientadas a promover el acceso a la propiedad agraria y a la literatura sobre formalización de tierras.

\section{Metodología}

Para la elaboración de este artículo se utilizaron técnicas de investigación y análisis cualitativo y cuantitativo. En primer lugar, para 
la reconstrucción de los debates de la ANC, se realizó un trabajo de archivo en el cual se consultaron 144 gacetas y actas de la Plenaria y la Comisión Quinta de la ANC publicadas entre febrero y julio de 1991. En segundo lugar, se sistematizaron todos los documentos de la ANC en los que se propusieron y discutieron aspectos relacionados con el acceso a la propiedad rural. Luego, se realizó una sistematización y análisis de los documentos jurídicos y de política pública de los seis programas nacionales de formalización identificados en el curso de la investigación. Por último, se presentan y analizan los resultados del sondeo aplicado en el 2018 por el Observatorio de Restitución y Regulación de Derechos de la Propiedad Agraria (ORRDPA) a la población de los municipios de Ramiriquí, Boyacá y Santander de Quilichao, Cauca, ${ }^{1}$ zonas donde se adelantaron programas de formalización.

La importancia de contrastar los debates de la ANC, los programas de formalización y los datos que arroja el sondeo permiten dos cosas. En primer lugar, evidencian la distancia existente entre los fines planteados por la Constitución, los programas de formalización que afirman desarrollarlos y la experiencia de quienes han participado en estos programas. En segundo lugar, a los programas de formalización los acompaña la falta de evidencia empírica que esperamos cubrir a través de las tres fuentes de información que presentamos. Como mencionamos en la introducción, los beneficios de la formalización dependen del contexto en que se aplican (Ubink, 2009). Por esto, un análisis de los programas en concreto permite analizar si estas políticas cumplen con sus objetivos y los fines constitucionales relacionados con el acceso a tierras.

\section{La relación entre los programas de formalización con el acceso a tierras del artículo 64 de la Constitución Política}

La formalización de tierras en Colombia se ha utilizado de dos maneras: como parte de las estrategias de promoción de otras políticas

Sondeo realizado por el ORRDPA en el marco del proyecto de investigación Formalización de derechos de propiedad agraria e (in) seguridad: ¿una relación de doble vía?, financiado por Colciencias. 
públicas y como política pública independiente que pretende disminuir la informalidad en la tenencia de la tierra. Sin embargo, ambos tipos de políticas de formalización coinciden en algo: se fundamentan en brindar acceso a la propiedad para la población rural y desarrollar el artículo constitucional 64. En esta sección, definiremos jurídicamente qué entendemos por formalización. Luego, describiremos los dos tipos de programas de formalización que identificamos se han implementado en el país. Finalmente, mostraremos la relación que el Estado colombiano trazó entre estos y el artículo constitucional 64.

\section{La formalización como concepto jurídico}

Definimos formalización como todos los procedimientos a través de los cuales una persona busca adquirir el título de propiedad sobre un predio o realizar el respectivo registro del título con miras a consolidar el derecho de propiedad. Estos procedimientos están dirigidos a cumplir con los requisitos legales que en su momento se omitieron o que se consolidaron después de detentar la posesión material del bien. Para explicarlos, hemos separado los procedimientos en 4 categorías:

i. Resolver problemas con los títulos que no cumplen con las formalidades y solemnidades que ordena la ley.

ii. Facilitar el registro de los títulos que cumplen con las formalidades que exige la ley.

iii. Sanear los problemas derivados de la falsa tradición (notarial o judicialmente).

iv. Obtener una sentencia que declare la prescripción adquisitiva de dominio. $^{2}$

Los dos primeros procedimientos buscan resolver las dificultades derivadas del sistema de registro de la propiedad inmueble, copiado del

2 A pesar de que las posesiones inscritas se cuentan entre los códigos que emplea la Superintendencia de Notariado y Registro (Resolución 11885 de 2016 e Instrucción Administrativa Número 11 de 2017) para la falsa tradición, la posesión es un derecho precario e imperfecto que se puede transferir. El comprador puede sumar la posesión que compra a la posesión que empieza a realizar sobre el bien con miras a lograr la prescripción adquisitiva (Código Civil, artículo 778). 
modelo francés (Reyes, 2016), exigiendo un título con determinadas formalidades y su registro en la Oficina de Registro de Instrumentos Públicos - ORIP- (Código Civil, artículo 756). Frente al título, cuando el acto o negocio jurídico se extiende en documento privado o se realiza un negocio de palabra, este no cumple con la solemnidad de la escritura pública que establece el Código Civil y por tanto es inadecuado para transferir el derecho de dominio (Código Civil, artículo 1857). Tratándose de bienes herenciales, su partición debe constar en escritura pública o en la respectiva sentencia, que hace las veces de título. Sobre la venta de derechos herenciales trataremos más adelante al explicar la falsa tradición. Ahora bien, suponiendo que el título cumple con la formalidad, su falta de registro implica que la tradición no se perfecciona (Código Civil, artículo 756) o que el bien asignado durante la partición sea efectivamente del dominio privado del heredero (Código Civil, artículo 757).

Además, existen consideraciones prácticas que también dificultan la transferencia del derecho de propiedad. En departamentos como Arauca, Meta y Bolívar el tiempo promedio de desplazamiento hasta las ORIP es de más de dos horas (Abril-Bonilla et al., 2019), lo que representa una pérdida de tiempo de trabajo y costos elevados para los campesinos (Peña \& Zuleta, 2018). Por otra parte, el pago de derechos notariales, de impuestos y tasas de registro (departamentales y nacionales) eleva los costos, dificultando que los campesinos propietarios de pequeñas parcelas realicen todos los trámites y formalidades establecidas en la ley por los altos gastos que deben asumir (Peña \& Zuleta, 2018; Acero E Parada, 2019).

El tercer tipo de procedimientos son aquellos dirigidos a sanear la falsa tradición ${ }^{3}$ (Decreto 1250, 1970, artículo 7; Ley 1579, 2012,

3 "En este sentido, se entiende por falsa tradición la realizada inadecuada o ilegalmente, sea porque no existe título o porque falta un modo de adquisición de los previstos por el legislador, correspondiendo a circunstancias como los títulos de non domine, donde no se posee el dominio sino títulos diferentes a la propiedad o el dominio, a las enajenaciones de cosa ajena, o las realizadas sobre una cosa sobre la cual no se tiene propiedad o dominio, por tenerlo otra persona; o las circunstancias de dominio incompleto porque no se tiene la totalidad del dominio, al haberlo adquirido de persona que sólo tiene parte de él; o también los eventos correspondientes a transferencia de derechos herenciales sobre cuerpo cierto o enajenaciones de cuerpo cierto teniendo únicamente derechos de cuota. Una adquisición viciada continúa siendo viciada y los diferentes actos dispositivos o transmisivos que se realicen 
artículo 8). A diferencia de los problemas con el título o su falta de registro, en que el vendedor es efectivamente el titular del derecho de dominio, en la falsa tradición el título transmite otros derechos que no son el derecho de dominio o no transmite ningún derecho, como en la venta de cosa ajena. Por ejemplo, cuando se venden los derechos y acciones herenciales sobre un predio. En estos casos, a pesar de que el heredero vendedor tiene un derecho sobre la universalidad de los bienes del causante, hasta que no se le asigne un bien en particular no puede reclamar como suyo determinado bien.

Para sanear los problemas derivados de la falsa tradición, algunos programas plantean la posibilidad de adelantar las respectivas sucesiones por notaría en el caso de ventas realizadas por herederos, para que luego el heredero vendedor pueda realizar la respectiva escritura pública a favor del comprador que ya detenta la posesión material del bien $^{4}$ (USAID \& ANT, 2018). Esta estrategia también es viable para las compraventas, donaciones y remates de los gananciales del cónyuge o compañero permanente supérstite. ${ }^{5}$ Sin embargo, esta posibilidad debe ser analizada desde una perspectiva de costos y beneficios, pues pasados 5 años de la venta de las acciones y derechos herenciales o gananciales por parte del vendedor, el comprador podría iniciar un proceso de prescripción adquisitiva de dominio.

Finalmente, se presentan los supuestos de la compraventa de posesiones con antecedentes registrales (Código Civil, artículo 762) de mejoras en predio ajeno, ventas de cosa ajena y ventas de cuerpo cierto, teniendo únicamente derecho de cuota. ${ }^{6}$ En el primer caso, el poseedor transmite un derecho precario e imperfecto al comprador, que espera perfeccionar el derecho cuando se cumpla el tiempo señalado en la ley para la usucapión. En los demás casos, estos negocios pueden ser

no purgan la irregularidad. Se trata de un derecho irregular, no apto para reivindicar, al no tratarse del derecho de dominio" (Sentencia SC10882, 2015).

4 Códigos 0601, 0607, 0610, 0613 y 0617 de la Resolución 11885 de 2016 de la Superintendencia de Notariado y Registro.

5 Códigos 0602, 0606, 0611, 0614, 0615 y 0622 de la Resolución 11885 de 2016 de la Superintendencia de Notariado y Registro.

6 Códigos 604, 605, 608 y 618 de la Resolución 11885 de 2016 de la Superintendencia de Notariado y Registro. 
un justo título ${ }^{7}$ que, aunado a la buena fe del comprador al momento de adquirir la posesión material del bien (Código Civil, artículo 764), lo faculta para adquirir el derecho de dominio vía prescripción adquisitiva ordinaria (Código Civil, artículo 2528). En todos los supuestos analizados en este párrafo, la sentencia es el título que debe registrarse en la ORIP para consolidar el derecho de dominio.

Ahora bien, el proceso de formalización, que como hemos explicado consiste en cumplir con una serie de requisitos que en su momento fueron omitidos o para demostrar que se han configurado los requisitos que la ley establece para la ocurrencia de la usucapión, solo puede adelantarse sobre bienes privados. En ese sentido, este procedimiento no aplica a los baldíos porque hacen parte de los bienes públicos, clasificados en (i) bienes de uso público, (ii) bienes fiscales y (iii) bienes fiscales adjudicables o baldíos. ${ }^{8}$ Independientemente de sus características, sobre estos bienes pesa una protección especial que los hace imprescriptibles (artículo 63 CP; artículo 413, numeral 4 CPC; artículo 375, numeral 4, CGP).

En el caso particular de los baldíos, para obtener el título se requiere de un acto administrativo facultativo de la autoridad agraria que se denomina resolución de adjudicación. Según la jurisprudencia de la Corte Constitucional (Sentencia T-488/2014 y Sentencia T-567/17) no es posible adquirir la propiedad sobre estos predios a través de procesos de pertenencia. Esta interpretación ha sido avalada por la Corte Suprema de Justicia en sede de revisión de tutela (Sentencia STC5005-2020). Aunque el asunto aún no se ha zanjado doctrinariamente, pues algunos jueces permiten la usucapión haciendo aplicación de las presunciones de la Ley 200 de 1936 (Verdad Abierta, 2020), la postura mayoritaria de la Corte Suprema de Justicia se adhiere a los pronunciamientos de la

7 "En materia de justo título fundamentalmente se exige que en realidad exista. Por ello no lo es el falsificado; el conferido por mandatario o representante legal de otra persona sin serlo; el que adolece de nulidad; y el simplemente putativo. Pero la venta real, aunque lo sea de cosa ajena, es justo título posesorio. No porque la cosa sea ajena, sino porque la venta, como título, respalda en derecho para la usucapión el animus domini del comprador de buena fe" (Sentencia del 27 de febrero de 1962, G. J., t. XCVIII, p. 52).

8 Consejo de Estado, Sala de lo Contencioso Administrativo-Sección Primera, Sentencia del 12 de noviembre de 2019, Radicado: 50001-23-31-000-2005-00213-01(AP) 
Corte Constitucional..$^{9}$ En ese sentido, si bien la adjudicación y la formalización son mecanismos de regularización de derechos de propiedad, parten de supuestos jurídicos distintos y tienen requisitos diferentes.

Por tanto, incluir la titulación de baldíos dentro de la formalización es un error doctrinal, pues como explicamos la adjudicación de los baldíos es un acto potestativo de la autoridad agraria ${ }^{10}$ que no depende del cumplimiento de ciertos requisitos. El ocupante que cumpla con las condiciones establecidas ${ }^{11}$ en la legislación agraria podrá, como mucho, tener una mera expectativa de derecho sobre el predio. En contraste, el cumplimiento de las formalidades pretermitidas o de los requisitos legales para usucapir consolidan el derecho de propiedad, sin que se requiera el concurso de la voluntad de autoridad alguna. El trámite ante las notarías y la ORIP se limita a un control de legalidad y verificación del cumplimiento de los documentos y actos exigidos por la ley. En los procesos de pertenencia, la sentencia del juez surte efectos declarativos, por lo que el derecho se consolida por el paso del tiempo (el lapso requerido se determina a partir de la existencia o no de un justo título) y el ánimo de señor y dueño con que actúa el poseedor.

\section{Los programas de formalización en Colombia}

Como ya lo advertimos inicialmente, hemos identificado dos tipos de programas de formalización en el país. Los primeros son aquellos utilizados como estrategias de promoción de otras políticas. Los segundos son los programas de formalización como políticas públicas.

9 Ver: Sentencias STL 5308-2020; Sentencia STC 3003-2020; Sentencia STC 1037-2020; Sentencia STC 2600-2019. Los salvamentos de voto del magistrado Luis Armando Tolosa muestran una postura divergente.

10 Si bien es cierto que los baldíos tienen una destinación especial principal para cumplir el mandato del artículo 64 de la Constitución Política, desarrollado en la Ley 160 de 1994, el Decreto Ley 902 de 2017 y en la Sentencia C-077 de 2017 de la Corte Constitucional, por lo que no puede dárseles una destinación diferente a estos bienes públicos, el propio acto de otorgar la adjudicación es potestativo.

11 Por ejemplo, las condiciones establecidas en los artículos 4 y 5 del Decreto Ley 902 de 2017 o el artículo 2.14.10.4.1 del Decreto Único Reglamentario del Sector Administrativo Agropecuario, Pesquero y de Desarrollo Rural. 
Bajo esta categoría agrupamos los programas de formalización que se han desarrollado con el objeto de impulsar las políticas de disminución de cultivos de uso ilícito (Peña et al., 2020). Estos programas parten de la premisa de que existe una relación entre la presencia de cultivos ilícitos y la informalidad de la tierra, por lo cual, consideran que la titulación de los predios es un mecanismo para evitar la siembra de este tipo de plantaciones (Peña et al., 2019; Muñoz-Mora et al., 2018; Garzón E Riveros, 2018). Bajo esta perspectiva, la formalización es vista de dos maneras. Por una parte, como incentivo positivo para la disminución de cultivos ilícitos porque se promete la asistencia estatal para titular los predios y la entrega de bienes y servicios a cambio de que los usuarios de estas políticas sustituyan o no realicen nuevos cultivos de uso ilícito. Por otra, como incentivo negativo porque al tener la propiedad formal el Estado puede aplicar la extinción de dominio en los predios con cultivos de uso ilícito (Peña et al., 2020; Muñoz-Mora, 2018).

En Colombia hemos identificado cuatro programas que han utilizado la titulación como mecanismo para incentivar la disminución de cultivos de uso ilícito en Colombia. El primero se desarrolló en Antioquia entre 2008 y 2013 y fue ejecutado en las regiones del bajo Cauca, nordeste, norte y oriente del Departamento (Gobernación de Antioquia y Oficina de Naciones Unidas contra la Droga y el Delito, 2010). Este programa tenía por objeto disminuir la presencia de cultivos ilícitos en el departamento mediante la entrega y asistencia de proyectos productivos, con un componente de tierras enfocado en la titulación de 200 predios en las regiones intervenidas.

El segundo programa se desarrolló en los municipios de Los Andes Sotomayor y Linares en el Departamento de Nariño entre 2013 y 2017 (Ministerio de Justicia y Oficina de Naciones Unidas contra la Droga y el Delito, 2013). El programa pretendió disminuir la presencia de cultivos de uso ilícito mediante asistencia estatal para implementar alternativas económicas lícitas y un programa de formalización de tierras que aspiraba a titular 1200 predios (Oficina de Naciones Unidas contra la Droga y el Delito, 2017). 
El tercer programa es Formalizar para sustituir, una estrategia impulsada desde 2016 hasta la fecha por la Agencia Nacional de Tierras (ANT) a nivel nacional con el objeto de desincentivar los cultivos de uso ilícito mediante la titulación de predios informales. La meta del programa es adelantar 7300 procesos de formalización en diferentes departamentos (ANT y Oficina de Naciones Unidas contra la Droga y el Delito, 2016; 2018a).

El último programa que identificamos en esta categoría es el proyecto impulsado desde 2018 por la ANT específicamente para la Zona de Reserva Campesina (ZRC). Este proyecto pretende disminuir los cultivos de uso ilícito en la ZRC de la Perla Amazónica, ubicada en Puerto Asís, Putumayo y la ZRC del Valle del río Cimitarra ubicada en los municipios de Remedios y Yondó, en Antioquia, y Cantagallo y San Pablo, en Bolívar (ANT y Oficina de Naciones Unidas contra la Droga y el Delito, 2018b). El objetivo de este programa fue la titulación de 1670 predios en las dos ZRC descritas.

\section{La formalización como política pública independiente}

En esta categoría identificamos dos programas que se caracterizan porque su único objetivo es lograr la titulación de las tierras. Estas políticas son el Programa presidencial para la formalización de la propiedad y la modernización de la titulación predial (Programa Presidencial), que se desarrolló entre 1997 y 2007, y el Programa Nacional de Formalización de los Predios Rurales (Programa Nacional), implementado entre 2010 y 2015. ${ }^{12}$ Actualmente la ANT continúa con la ejecución de procesos de formalización que responden a las funciones establecidas para la entidad, pero no tenemos evidencias que respondan a una política pública formulada de forma comprensiva y coherente.

E1 Programa Presidencial fue financiado por el BID, a través del convenio CO0157 de 1997. Los objetivos iniciales del Programa Presidencial fueron facilitar el acceso de los propietarios rurales y urbanos al sistema

12 El análisis que se presenta a continuación sobre los programas está basado en un reporte publicado por el Observatorio de Restitución y Regulación de Derechos de Propiedad Agraria (2019). 
financiero, estimular la producción y las inversiones para generar crecimiento económico y dinamizar el mercado de tierras. Con el gobierno de Andrés Pastrana los objetivos cambiaron y el Programa Presidencial se concentró en la modernización del catastro y el registro, dejando de lado la titulación. Según la evaluación del BID (2014), el programa ejecutó recursos para titulación desde el 14 de marzo de 1998 hasta mayo del 2000, momento en el que se reestructuraron los objetivos.

Ahora bien, la información disponible sobre la titulación ejecutada en esos dos años por el Programa Presidencial es escasa o inexistente. Las entidades encargadas del diseño y ejecución del programa (DNP, DAPRE y MinCIT) ${ }^{13}$ no cuentan con datos consolidados sobre su implementación y el cumplimiento de objetivos. El único dato disponible es el suministrado por el BID en su informe de seguimiento: 5091 resoluciones de adjudicación de baldíos. A pesar de que se trata de un esfuerzo importante en materia de titulación, el programa en realidad no formalizó predios de propiedad privada en manos de poseedores.

En contraste, el Programa Nacional, creado a través de la Resolución 452 de 2010 y modificado por la Resolución 181 de 2013 del Ministerio de Agricultura y Desarrollo Rural, tenía como objetivos promover el acceso a la propiedad de la tierra y mejorar la calidad de vida de los campesinos; impulsar y coordinar acciones encaminadas a regularizar la tenencia individual y colectiva de los predios rurales; asegurar los derechos de propiedad de la población campesina, y consolidar una cultura de la formalidad de la propiedad rural. Como se infiere de sus objetivos, el Programa Nacional buscaba desarrollar los mandatos del artículo constitucional 64.

Además, la Resolución 181 de 2013 establece expresamente que el programa está dirigido únicamente a predios de propiedad privada (artículo 1) y crea la Zona de Formalización Masiva (ZFM). ${ }^{14}$ Esta limitación responde a la idea de acoplar el Programa Nacional a la Ley 1561 de 2012 “Por la cual se establece un proceso verbal especial para

13 Según consta en sus respuestas a derechos de petición: DNP (Radicado 20175600422901 del 2017) y DAPRE y MinCIT (ambos con el radicado E- 2017-613930 de la Procuraduría del 2017).

14 Son los municipios elegidos para implementar el mecanismo de barrido predial e iniciar con los procedimientos de formalización. 
otorgar títulos de propiedad al poseedor material de bienes inmuebles urbanos y rurales de pequeña entidad económica, sanear la falsa tradición y se dictan otras disposiciones", que ordena el rechazo de plano de la demanda cuando se advierta que esta recae sobre bienes baldíos (artículo 6, numeral 1).

\section{Relación entre programas de formalización con el acceso a tierras y el artículo constitucional 64}

Como se indicó anteriormente, los dos tipos de políticas de formalización que se han implementado en el país se justificaron invocando el artículo 64 de la Constitución o la obligación de brindar acceso a la propiedad rural. Como se muestra en la tabla 1, solo uno de los programas analizados no hace referencia a ninguno de estos dos aspectos, uno de los programas hace referencia únicamente al acceso a tierras y el resto hace referencia a los dos elementos. Esto nos muestra claramente la relación que traza el Estado entre la formalización, el acceso a tierras y el artículo constitucional 64.

Tabla 1. Relación entre programas de formalización, el acceso a tierras y el artículo constitucional 64

\begin{tabular}{|l|c|c|}
\hline \multicolumn{1}{|c|}{ Programa } & $\begin{array}{c}\text { Cita } \\
\text { explícitamente } \\
\text { el artículo 64 }\end{array}$ & $\begin{array}{c}\text { Menciona explícitamente } \\
\text { que el programa brindará } \\
\text { acceso a tierras }\end{array}$ \\
\hline $\begin{array}{l}\text { Programa Presidencial de } \\
\text { formalización de 1997 }\end{array}$ & No & Sí \\
\hline $\begin{array}{l}\text { Programa de formalización para incentivar } \\
\text { la sustitución de Antioquia de 2008 }\end{array}$ & No \\
\hline $\begin{array}{l}\text { Programa Nacional de } \\
\text { formalización de 2010 }\end{array}$ & Sí & Sí Sí \\
\hline $\begin{array}{l}\text { Programa de formalización para incentivar } \\
\text { la sustitución de Nariño de 2013 }\end{array}$ & Sí \\
\hline $\begin{array}{l}\text { Programa de formalización para incentivar } \\
\text { la sustitución de la ANT de 2016 }\end{array}$ & Sí & Sí \\
\hline $\begin{array}{l}\text { Programa de formalización para incentivar } \\
\text { la sustitución de la ANT para ZRC de 2018 }\end{array}$ & Sí & Sí \\
\hline
\end{tabular}


La persistencia del Estado por establecer esta relación fue reconocida en recientes informes que analizan el cumplimiento de los compromisos sobre acceso a tierras que se establecieron en el Acuerdo Final de Paz (AFP). La Procuraduría General de la Nación encontró que la ANT presentó resultados que corresponden a programas de formalización como desarrollo de la política de acceso a la propiedad agraria para campesinos sin tierra o con tierra insuficiente (Procuraduría General de la Nación, 2020). En este punto coincide el informe de seguimiento al AFP realizado por distintos congresistas, donde se muestra que el Gobierno reporta datos de las políticas de formalización y de dotación de tierras sin diferenciarlas (Congreso de Colombia, 2019).

Lo anterior nos permitió mostrar que el Estado colombiano encuentra una relación entre las políticas de formalización con el acceso a tierras y el artículo 64 de la Constitución. Como explicamos, en los documentos de creación, diseño y ejecución de los programas de formalización identificados se afirma que mediante estos se está cumpliendo con la obligación estatal de brindar acceso a tierras conforme lo establece el artículo constitucional referenciado. Igualmente, queda claro que se persiste en dicha relación, pues los informes realizados por diferentes congresistas y la Procuraduría concluyen que el Estado incluye los resultados de los programas de formalización entre los reportes de acceso a tierras.

A continuación, analizaremos si los programas de formalización cumplen con los objetivos constitucionales de promover el acceso a tierras para la población rural, otorgar acceso a créditos y dotación de bienes públicos establecidos en el artículo 64 de la Constitución. Para este análisis recurriremos a los fines que buscó la ANC al incluir este artículo en la Carta Política.

\section{Los objetivos constitucionales de la promoción del acceso a la tierra}

Establecida la relación que el Estado colombiano traza entre los programas de formalización y el mandato de brindar acceso a tierras del artículo 64 de la Constitución Política, es importante precisar los 
objetivos de la ANC al redactar esta disposición. Para ello, presentaremos un breve recuento de los debates de la ANC que estructuraron el artículo 64 y los elementos del acceso a tierras que fueron definidos en el proceso constituyente. Hecho este recuento, concluiremos que los objetivos del acceso a la propiedad rural definidos por la ANC son (i) La obligación del Estado de promover la apropiación de la tierra por parte de la población del sector rural, (ii) Que el acceso a la tierra esté acompañado de la entrega y dotación de bienes, servicios y obras de infraestructura en el campo y (iii) El acceso a la tierra debe ser redistributivo y buscar la democratización de la propiedad, utilizando como herramienta primordial la expropiación administrativa.

En la ANC de 1991, el campesinado colombiano no estuvo representado por organizaciones que defendieran sus intereses. La falta de representación generó que los temas relacionados con el sector agrario, en general, y sobre los derechos campesinos, en particular, no se consideraran como un aspecto prioritario de la agenda constituyente. Por lo anterior, en la ANC no existió una amplia discusión sobre las garantías que traería la nueva constitución para los campesinos (Güiza et al., 2020); de hecho, en el texto final no hay una referencia explícita a esta población (Peña Huertas et al., 2014; Peña Huertas, 2020).

Pese a lo anterior, en el desarrollo de la ANC se presentaron propuestas que generaron debates sobre puntos con incidencia en el sector rural. En relación con el acceso a la propiedad agraria y los mecanismos de acceso a esta, identificamos dos líneas de debate. La primera fue la propuesta sobre derechos agrarios, la cual concluyó con la creación de los artículos 64, 65 y 66 de la Constitución Política. En esta se delimitaron las obligaciones del Estado en torno al acceso a la propiedad para la población rural y las garantías con las que se realizaría. La segunda fueron las discusiones sobre la expropiación vía administrativa que se desarrollaron en el marco de los debates sobre el derecho de propiedad. Este aspecto es clave, pues la expropiación se pensó como mecanismo para hacer efectiva la dotación de tierras. A continuación, describiremos los principales puntos de ambas discusiones. 


\section{La ponencia sobre derechos agrarios: El acceso a la propiedad agraria y la dotación de bienes públicos}

La primera línea de debate relacionada con el sector rural y el acceso a la propiedad para la población campesina se impulsó a través de la propuesta titulada "Derechos agrarios", radicada en la Comisión Quinta por constituyentes electos por las listas de la AD-M19 y el Partido Conservador (Garzón et al., 1991). En la propuesta presentada por los constituyentes se propusieron seis artículos, de los cuales dos eran transitorios. Nos referiremos únicamente a los cuatro permanentes. En el primer artículo se pretendía consagrar el impulso de las actividades agropecuarias y agroindustriales; en el segundo, garantizar el acceso a la propiedad rural para los trabajadores del campo; en el tercero, se establecía la protección de las tierras de resguardo para uso de las comunidades indígenas, y, en el cuarto, se consagraría el fomento estatal para la dotación de bienes y servicios públicos en el sector rural para estimular el desarrollo productivo e integral del sector (Garzón et al., 1991).

Los motivos expuestos en el proyecto y el articulado presentados nos permiten afirmar que los constituyentes perseguían tres objetivos. Primero, impulsar el desarrollo económico de los sectores productivos del campo, tanto para el sector agroindustrial como para la economía campesina. Segundo, fomentar la disponibilidad de bienes, servicios e infraestructura en el sector rural. La educación, las obras de infraestructura y de servicios, el acceso a crédito, la asistencia técnica, entre otros mecanismos, se consideraron elementos necesarios para mejorar la calidad de vida de la población rural. Por último, la democratización de la tierra, a través del acceso a tierras garantizado por el Estado. Sin embargo, no se proponía una herramienta específica para concretarlo.

Estos puntos se mantuvieron durante el trámite del proyecto en la Plenaria de la ANC aunque su contenido fue variando. La ponencia radicada para dar primer debate en la plenaria no presentó modificación alguna en su articulado ni en su justificación (Asamblea Nacional Constituyente, 1991e). No obstante, en la presentación que hizo de la ponencia en la Plenaria el constituyente Marcos Chalita, quien asumió el liderazgo de la ponencia, las justificaciones variaron aunque los tres 
objetivos descritos permanecieron. La exposición realizada relacionaba la totalidad del proyecto con la necesidad de sentar las bases constitucionales para la implementación de una reforma agraria viable para cumplir los tres ejes descritos en el proyecto inicial. De esta explicación del proyecto resaltamos dos aspectos sobre la propiedad rural. En primer lugar, se declaró que el acceso a tierras debía estar acompañado con el equipamiento de bienes y servicios en las zonas rurales en las que se entregara tierra a los campesinos. En segundo lugar, se relacionó este proyecto con la necesidad de implementar la expropiación vía administrativa que se propuso en la ponencia sobre el articulado de propiedad (Presidencia de la República, 1991d).

En el segundo debate en la Plenaria de la ANC se analizó la propuesta de modificaciones presentada por una subcomisión nombrada para analizar la iniciativa del articulado (Asamblea Nacional Constituyente, 1991f). Los cambios en el articulado consistieron en reducir a tres artículos la iniciativa, conservando los tres objetivos iniciales. De esta manera, los artículos propuestos por la subcomisión conservaron las finalidades de impulsar el desarrollo de la economía agraria, brindar acceso a tierras a la población rural y dotar de bienes y servicios al campo colombiano (Asamblea Nacional Constituyente, 1991f).

Los debates en torno a la ponencia de la subcomisión se concentraron en dos puntos, de los cuales solo mencionaremos el relacionado con el acceso a tierras. Esta discusión giró en torno a si el Estado debería "garantizar" o "promover" el acceso a tierras. El debate se zanjó al escoger la palabra "promover" porque se argumentó que en el artículo de propiedad se estableció que el Estado promovería la propiedad, por lo cual se decidió conservar el mismo grado de intervención estatal en relación con el acceso a tierras rurales (Asamblea Nacional Constituyente, 1991f).

\section{Las discusiones sobre el derecho a la propiedad:}

La expropiación como mecanismo para impulsar la reforma agraria y el acceso a tierras

El tema de la expropiación fue presentado en varios proyectos de reforma constitucional. Como lo muestra la tabla 2, en distintas iniciativas radicadas por las instituciones estatales, los constituyentes y las 
entidades no gubernamentales manifestaron la necesidad de incluir la expropiación administrativa en la Constitución y argumentaron que era una herramienta necesaria para impulsar la reforma agraria y brindar acceso a tierras a la población rural.

Tabla 2. Propuestas de reforma constitucional de la ANC relacionadas con la expropiación para impulsar la reforma agraria

\begin{tabular}{|l|c|c|c|}
\hline \multicolumn{1}{|c|}{ Tipo de documento } & $\begin{array}{c}\text { Número } \\
\text { de Gaceta }\end{array}$ & Autor & Fecha \\
\hline Propuesta de reforma constitucional 02 & 5 & Gobierno Nacional & $15 / 02 / 1991$ \\
\hline Propuesta de reforma constitucional 04 & 6 & $\begin{array}{c}\text { Cornelio Reyes, } \\
\text { Raimundo Emiliani }\end{array}$ & $18 / 02 / 1991$ \\
\hline Propuesta de reforma constitucional 06 & 7 & Diego Uribe Vargas & $18 / 02 / 1991$ \\
\hline $\begin{array}{l}\text { Propuesta de reforma } \\
\text { constitucional 83, 92 y 93 }\end{array}$ & 24 & $\begin{array}{c}\text { Lorenzo Muelas, } \\
\text { Horacio Serpa }\end{array}$ & $20 / 03 / 1991$ \\
\hline $\begin{array}{l}\text { Propuesta de reforma } \\
\text { constitucional 128 y 130 }\end{array}$ & $26 a$ & $\begin{array}{c}\text { Ivan Marulanda, } \\
\text { Eduardo Espacio }\end{array}$ & $26 / 03 / 1991$ \\
\hline $\begin{array}{l}\text { Propuesta de reforma constitucional } \\
\text { no gubernamental 04 }\end{array}$ & 34 & $\begin{array}{c}\text { Colegio Altos } \\
\text { Estudios Quirama }\end{array}$ & $2 / 04 / 1991$ \\
\hline
\end{tabular}

La propuesta de constitución que presentó el gobierno Gaviria abrió la discusión sobre la necesidad de introducir esta herramienta jurídica. La justificación brindada fue la necesidad de impulsar tres programas específicos: la reforma agraria, la reforma urbana y la construcción de obras públicas (Asamblea Nacional Constituyente, 1991a). Esta propuesta la replicaron los constituyentes que presentaron la ponencia sobre el derecho de propiedad y fue ampliamente debatida en el curso de la ANC (Asamblea Nacional Constituyente, 1991b).

En el desarrollo de las sesiones de la Comisión Quinta, el gobierno nacional defendió la inclusión de este mecanismo. Para ello, argumentó que la expropiación administrativa era una herramienta idónea y ágil, pues históricamente la implementación de los planes de reforma agraria fue lenta, principalmente por las demoras del trámite judicial que autorizaba la medida (Presidencia de la República, 1991a; 1991b).

La ponencia presentada sobre derechos de propiedad para primer debate en la Plenaria de la ANC acogió parcialmente la propuesta del 
Gobierno nacional. Se propuso la consagración de la expropiación administrativa, pero no se limitó a los tres aspectos presentados en el proyecto gubernamental. En cambio, la propuesta de los ponentes dejó a consideración del Congreso los eventos en los cuales sería permitida la expropiación desde el ejecutivo (Asamblea Nacional Constituyente, 1991c). Los constituyentes defendieron la expropiación basándose en la función social de la propiedad y su democratización. Afirmaron que la expropiación era una herramienta conducente para hacer prevalecer el interés general sobre el particular, como la función social lo requiere, y le permite al Estado brindar acceso a la propiedad para quienes no la tienen, cumpliendo el fin de justicia social al que aspira la democratización de la economía (Asamblea Nacional Constituyente, 1991c).

En el desarrollo de los debates sobre las propuestas y fundamentos del gobierno y de los ponentes, las reacciones se dividieron principalmente en dos. Desde los sectores conservadores de la ANC se rechazó la medida de expropiación administrativa para impulsar la reforma agraria, argumentando que la falta de implementación de la reforma obedecía al poco interés de los anteriores gobiernos y no a la inexistencia de la expropiación. Además, este instrumento aumentaría la inseguridad jurídica en el campo (Presidencia de la República, 1991a; Asamblea Nacional Constituyente, 1991d). Por otro lado, miembros de la AD-M19 defendieron y acompañaron la propuesta. Se manifestó que la expropiación administrativa era una consecuencia lógica del interés de promover la reforma agraria (Presidencia de la República, 1991c; 1991d).

\section{La promoción del acceso a la tierra en la ANC: Los objetivos constitucionales}

El recuento que presentamos sobre las dos líneas de debate analizadas nos permite mostrar los objetivos de los constituyentes al consignar el artículo 64 de la Constitución y la forma en que percibían el acceso a tierras para la población rural. Los fines fueron los siguientes:

i. Se estableció la obligación del Estado de promover la apropiación de la tierra por parte de la población del sector rural. De esta forma, las instituciones públicas deben diseñar programas que permitan 
que las personas en contextos agrarios que no tengan o tengan poca tierra puedan acceder a esta.

ii. El acceso a la tierra debe estar acompañado de la entrega y dotación de bienes, servicios y obras de infraestructura en el campo. Los constituyentes concluyeron que los programas de dotación de tierras no pueden centrarse únicamente en mecanismos que faciliten el acceso a la propiedad agraria, estos también deben estar acompañados de inversión y asistencia estatal para los beneficiarios de estas políticas.

iii. El acceso a la tierra debe ser redistributivo y buscar la democratización de la propiedad, utilizando como herramienta primordial la expropiación administrativa. Tanto las iniciativas y debates sobre la ponencia de derechos agrarios, como las relacionadas con la expropiación en las discusiones sobre el derecho de propiedad coinciden en un punto: la relación entre el acceso a la tierra rural y la expropiación.

En el transcurso de la ANC, en ambas discusiones se enfatizó en la necesidad de implementar mecanismos de acceso a tierras que permitieran la redistribución de la propiedad y concluyeron que el mecanismo para implementarlos debería ser la expropiación administrativa. Esto nos permite afirmar que los constituyentes fijaron un rumbo claro para implementar el artículo 64 de la Constitución: el acceso redistributivo de la propiedad agraria.

\section{Peras y manzanas: E1 incumplimiento de los objetivos constitucionales del acceso a tierras por los programas de formalización}

En esta parte, compararemos el mandato del artículo constitucional 64 y los objetivos que fueron definidos por la ANC con la forma en que se han implementado los programas de formalización desarrollados en Colombia. Primero, analizaremos jurídicamente la operatividad de estos programas para mostrar que estas políticas no redistribuyen, por lo cual no se cumple con la finalidad establecida en la ANC. En segundo lugar, presentaremos los resultados de un sondeo realizado en zonas donde 
se han implementado estas políticas. Con ello, demostraremos que la formalización no cumple con la finalidad constitucional de dotación de bienes y servicios que deben acompañar el acceso a la tierra. Esto es un indicio de que la formalización, más que desarrollar el artículo 64, es una estrategia para consolidar el mercado de tierras.

\section{La operatividad jurídica de los programas de formalización: Títulos sin redistribución}

Es importante recapitular brevemente los diferentes procedimientos que se pueden implementar para formalizar: (i) cumplir con las formalidades pretermitidas en ciertos títulos, (ii) registrar los títulos que cumplen con las formalidades, (iii) sanear los problemas derivados de la falsa tradición y (iv) obtener la declaración de pertenencia. En ninguna de estas hipótesis se le facilita el acceso a un nuevo predio o a más tierra al usuario de la política. En contraste, en los casos del Subsidio Integral de Tierras (SIRA) o de la compra de predios para su ingreso en el Fondo Nacional de Agrario (FNA) es posible hablar una redistribución en el sentido que personas que carecían de tierra efectivamente acceden a ella a través de mecanismos de mercado, usando los subsidios que establecen estas herramientas.

Ahora bien, como anteriormente mostramos, existen dos tipos de programas de formalización con objetivos diferentes: acompañar las políticas públicas de sustitución de cultivos de uso ilícito y otorgar acceso a tierras como objetivo autónomo. En ninguno de los casos existe redistribución alguna de la tierra por la simple razón de que las personas que se vinculan a estos programas ya detentan la posesión material del predio y actúan como señores y dueños. Esto es algo que reconoce la literatura que trata sobre la formalización, afirmando que en últimas lo que estos procedimientos buscan es crear un mercado de tierras (Álvarez Roa, 2012), otorgar seguridad jurídica (Bruce, 2006) y garantizar el acceso a créditos (de Soto, 2001).

Ahora bien, como explicamos anteriormente, la formalización es un mecanismo de regularización de la propiedad diferente a la adjudicación de baldíos. Si bien en algunos casos la adjudicación entrega títulos a ocupantes que ya se encontraban en el predio, en otros casos facilita 
el acceso material a la tierra. Por tanto, incluir la adjudicación en la formalización induce a errores al momento de presentar las cifras sobre los programas de formalización porque "el gobierno está reportando, sin diferenciar, los datos de formalización y dotación de tierras, lo que no corresponde a lo establecido en el Acuerdo, ni en las metas definidas en el PND" (Congreso de Colombia, 2019, p. 55). Los acuerdos establecen una meta clara de acceso a tierras en los numerales 1.1.1, 1.1.2 y 1.1.3 que es diferente a la meta de formalización establecida en el numeral 1.1.5. En ese sentido, está mezclando mecanismos que efectivamente otorgan acceso a tierras con mecanismos que buscan consolidar el derecho de propiedad de personas que ya detentan la posesión material del bien y deben cumplir con ciertas formalidades para consolidar el derecho de propiedad. En otras palabras, están revolviendo peras con manzanas.

\section{Formalización y dotación de bienes $y$ servicios: Promesas incumplidas}

Por último, contrastaremos los elementos del artículo 64 de la Constitución con los resultados de un sondeo realizado por el ORRDPA en 2018 en Santander de Quilichao y Ramiriquí, lugares en los que se implementó el Programas Nacional. Si bien este programa se ejecutó en otros lugares dentro del territorio nacional, el trabajo de campo para realizar el sondeo se concentró en estos municipios por motivos de acceso. No obstante, estos municipios permiten verificar qué condiciones existían antes de la formalización de los predios y analizar si se modificaron después de la formalización.

El sondeo se realizó a 120 personas entre 18 y 78 años. De estas, 63 fueron de género femenino y 58 de género masculino. De las personas encuestadas, 113 se identifican como campesino o campesina. De las 120 personas encuestadas, 58 tenían el predio formalizado al momento de responder, 60 no lo tenían formalizado y dos no respondieron. Ahora bien, el sondeo no se realizó únicamente con usuarios y usuarias del programa de formalización, lo que hace imposible tener una evaluación completa de los efectos del programa en Ramiriquí y Santander de Quilichao. Por lo tanto, los datos que se exponen a continuación se desagregan tratando de verificar las ideas detrás de los programas que 
aparecen tanto en la literatura académica (Bruce, 2006; Besley, 1995; de Soto 2000; Acero \& Parada 2019), como en las justificaciones que citan los propios programas: dotación de bienes públicos (educación, salud y seguridad social), acceso a crédito, comercialización de productos y asistencia técnica.

En educación se espera que, al contar con títulos formales, mejore el acceso a este derecho. Es decir, debería existir mayor infraestructura de educación en las veredas con predios formales. No obstante, el sondeo muestra que de los 60 encuestados que no tenían el predio formalizado, 33 contaban con instituciones educativas en su vereda. De los 58 que tenían el predio formalizado, 35 no contaban con instituciones educativas en su vereda (figura 1).

Figura 1. ¿Hay una institución educativa en su vereda?

40

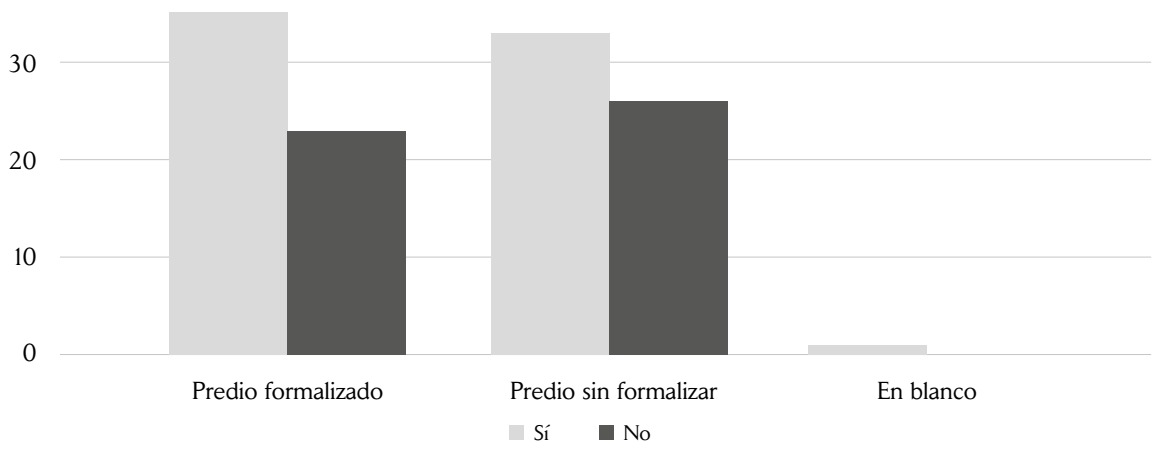

Así, el sondeo muestra que no hay una relación necesaria entre el acceso a instituciones educativas a nivel veredal y la formalización.

Por su parte, se esperaría que la salud y seguridad social también mejorarían con la formalización. Pero el sondeo muestra lo contrario: de las 60 que no tienen formalizado el predio, 52 no cotizan pensión y 57 tienen acceso a salud. En contraste, de las 58 que sí eran titulares del derecho de dominio, 51 no cotizan pensión y 55 tienen acceso a salud (figura 2).

Esto muestra que la formalización por sí sola no garantiza el acceso a la seguridad social. Adicionalmente, en materia de créditos, de los 120 encuestados, 51 tuvieron acceso a crédito antes del título. Solo 46 encuestados que obtuvieron el título respondieron cuando se les preguntó si habían accedido a créditos, 25 respondieron afirmativamente (figura 3). 
Figura 2. ¿Cuenta con acceso a la salud? ¿Cotiza seguridad social en pensión?

60

40

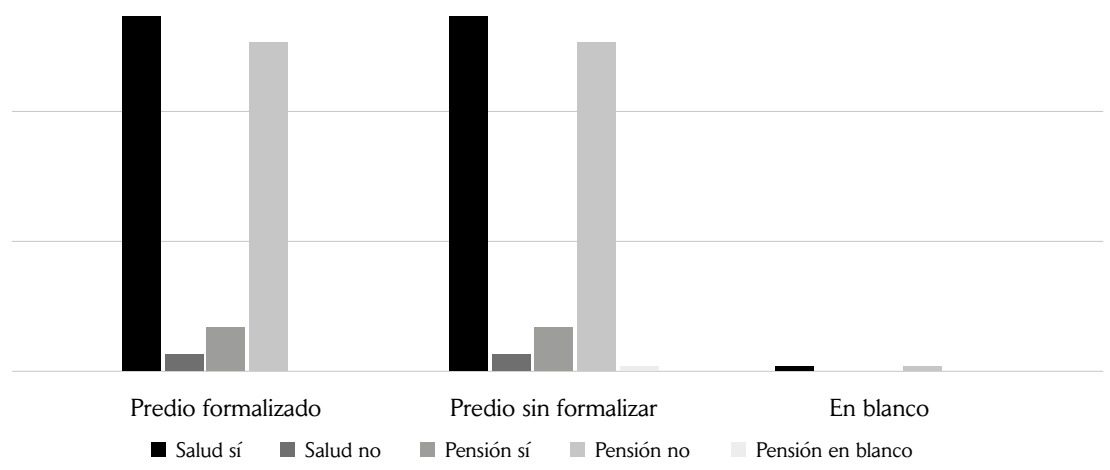

Figura 3. ¿Tuvo acceso a crédito?

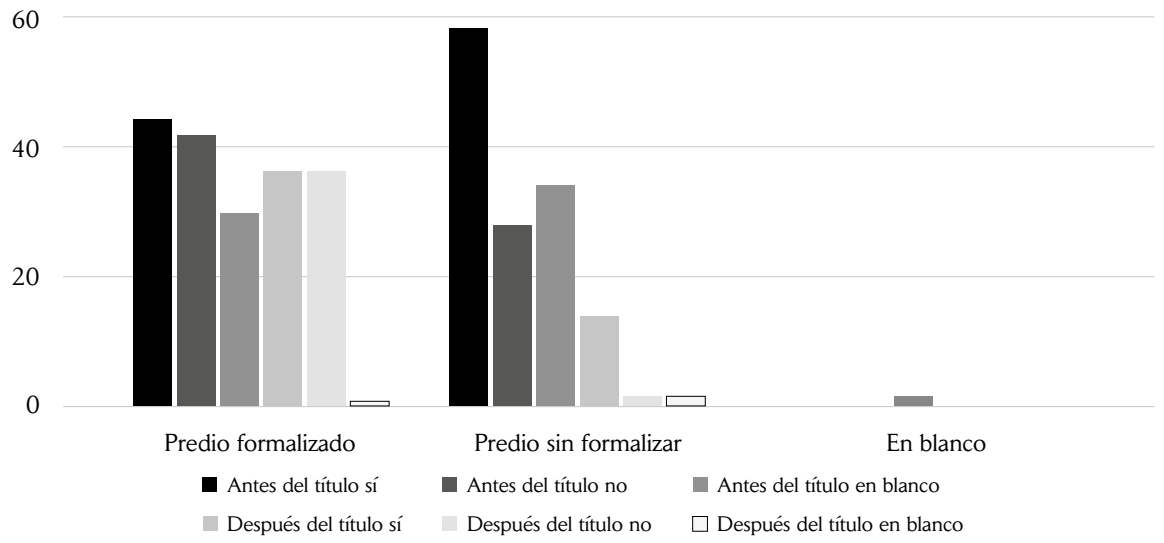

Los datos del sondeo muestran que tener un predio formalizado no es necesario para acceder a crédito. Esto va muy de la mano con los datos sobre la comercialización de productos. Antes del título, 76 encuestados dijeron que sí podían comercializar sus productos y 37 que no podían hacerlo. De esos 37, solo 2 respondieron que después del título podían comercializar sus productos (figura 4).

En cuanto a la existencia de mercados antes del título, 79 dijeron que sí había mercados antes del título y 36 que no había. De estos 36, ninguno respondió que después del título se crearan nuevos mercados (figura 5). 
Figura 4. ¿Puede comercializar sus productos?

60

40

20

0

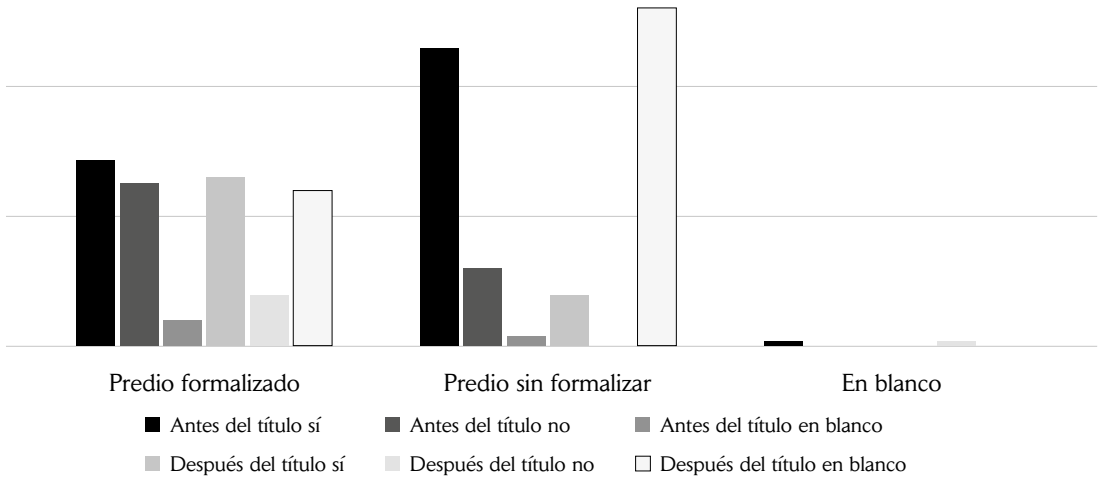

Figura 5. ¿Había mercados para comercializar sus productos?

60

40

20

0

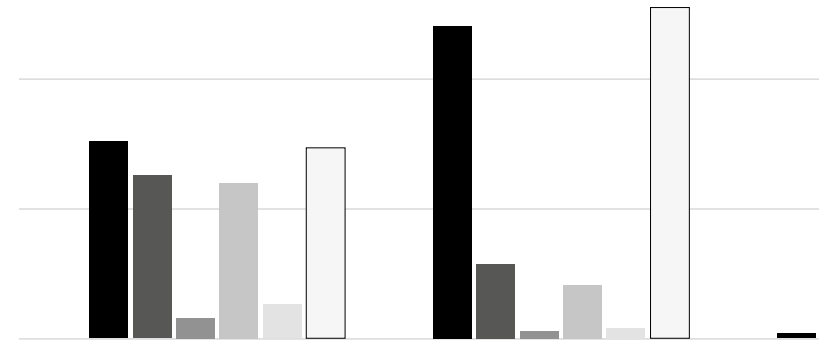

Predio formalizado

Predio sin formalizar

En blanco

- Antes del título sí

Antes del título no

Antes del título en blanco

Después del título sí

Después del título no

$\square$ Después del título en blanco

Por último, la asistencia técnica se dividió en estatal y no estatal. Del total de encuestados 103 no contaron con asistencia no estatal y 13 sí. De los 103, 47 obtuvieron título y solo 3 obtuvieron asistencia con estas entidades luego del título (figura 6).

Por su parte, la asistencia estatal se dio de la siguiente manera: 96 no contaron con asistencia técnica y 21 sí. De esos 96, 41 obtuvieron título y de estos solo 7 contaron con asistencia técnica del Estado (figura 7). 
Figura 6. ¿Ha tenido asistencia con entidades no estatales?

60

40

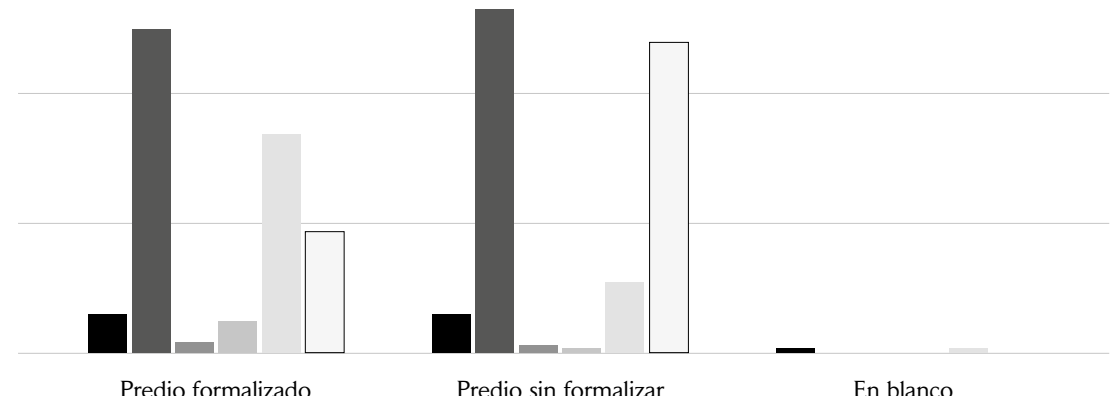

Predio formalizado

Predio sin formalizar

En blanco

- Antes del título sí

Antes del título no

Antes del título en blanco

Después del título sí

Después del título no

$\square$ Después del título en blanco

Figura 7. ¿Ha tenido asistencia técnica por parte del estado?

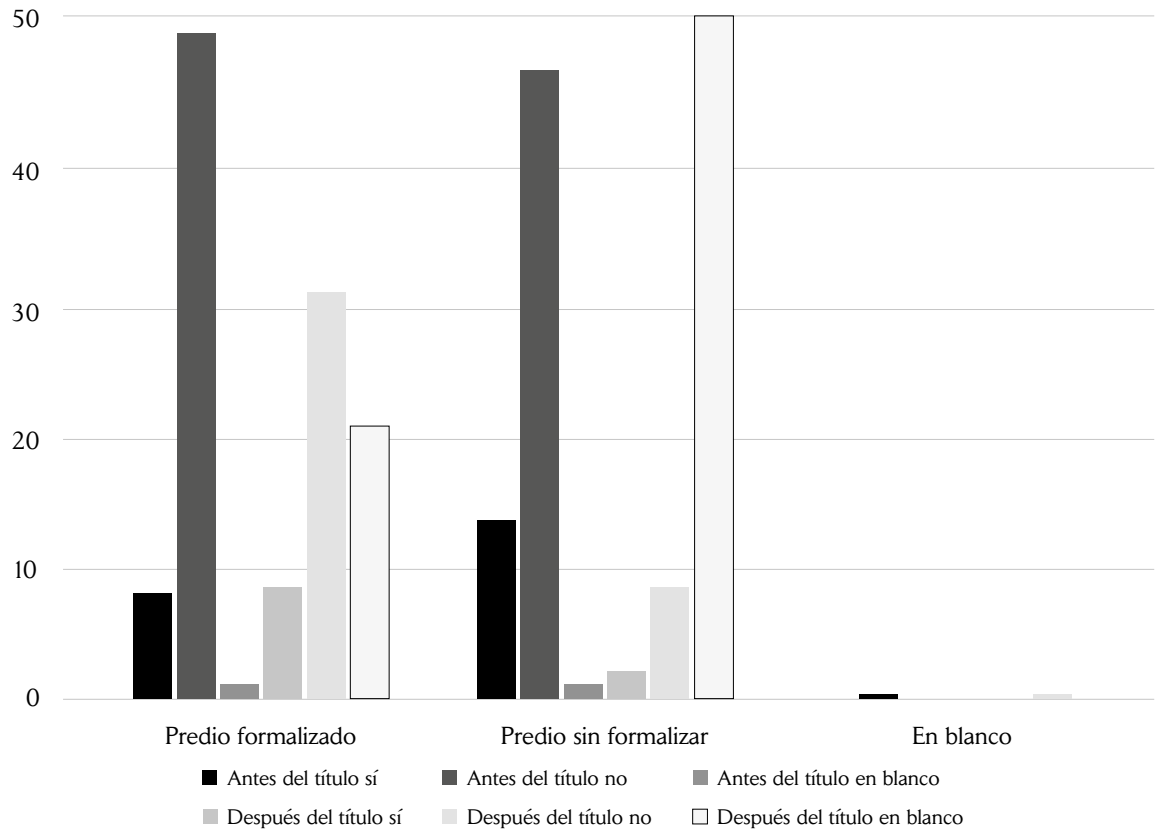

Este sondeo muestra la relación compleja que tiene la formalización con el desarrollo del campo. En todos los puntos evaluados sobre dotación de bienes y servicios se evidencia que las políticas de formalización no son suficientes para cumplir con esta meta. Ahora bien, falta por 
determinar si las condiciones de vida mejoran en términos generales para los usuarios y usuarias de estos programas. No obstante, para lograr eso se requiere una evaluación completa del programa, cosa que no se ha realizado hasta el momento.

\section{Conclusiones}

En este artículo se demostró que el Estado relaciona los programas de formalización con la obligación de promover el acceso a la tierra que establece el artículo 64 de la Constitución. Sin embargo, estos programas no cumplen con los fines establecidos por la ANC de 1991. Como se expuso, del análisis de los debates de la ANC concluimos que los objetivos sobre acceso a la propiedad rural son tres: (i) la obligación del Estado de promover la apropiación de la tierra por parte de la población del sector rural, (ii) que el acceso a la tierra esté acompañado de la entrega y dotación de bienes, servicios y obras de infraestructura en el campo y (iii) el acceso a la tierra debe ser redistributivo y buscar la democratización de la propiedad, utilizando como herramienta primordial la expropiación administrativa.

Al comparar estos objetivos constitucionales con los programas nacionales de formalización implementados en Colombia, vemos que estos son insuficientes por dos motivos: (i) La formalización no puede resolver el problema del acceso y democratización del acceso a tierras por la sencilla razón de que no busca (re) distribuir, sino otorgar títulos de propiedad y realizar el respectivo registro a fin de otorgar seguridad jurídica a personas que ya detentan la posesión material de la tierra y (ii) la forma en que se han implementado los programas de formalización no cumplen con el mandato de dotar de bienes y servicios a los procesos de acceso a tierras.

\section{Referencias}

Abril-Bonilla, N., Jiménez Nicholls, M., \& Uribe Larrota, L. (2020). iA formalizar!: disputas de lo campesino en el Alto Cauca. Antípoda. Revista de 
Antropología y Arqueología, (40), 79-102. https://doi.org/10.7440/antipoda40.2020.04

Abril-Bonilla, N., Valencia Herrera, M., Peña Huertas, R del P., Abondano Romero, A., Barrero Molina, C., Jiménez Nicholls, M. C., Lozano Valcárcel, A. J., Triana Ancinez, B., E Uribe Larrota, L. F. (2019) Laberintos institucionales: una mirada crítica a los programas de formalización de la propiedad rural en Colombia. Reporte semestral Observatorio de Restitución y Regulación de Derechos de Propiedad Agraria. ORRDPA. https://www.observatoriodetierras. org/wp-content/uploads/2019/12/laberintos-institucionales-2.pdf

Acero Vargas, C., \& Parada Hernández, M. (2019). ¿“De eso tan bueno no dan tanto"? La experiencia colombiana en formalización de tierras a la luz de la evidencia internacional. Análisis Político, 32(95), 82-103. https:// doi.org/10.15446/anpol.v32n95.80831

Agencia Nacional de Tierras y Oficina de Naciones Unidas contra la Droga y el Delito en Colombia. (2016). Convenio de cooperación internacional No. 112 de 2016. https://www.contratos.gov.co/consultas/detalleProceso. do?numConstancia $=16-4-5476902$.

Agencia Nacional de Tierras y Oficina de Naciones Unidas contra la Droga y el Delito en Colombia. (2018a). Adición No. 4 y prorroga No. 3 al Convenio de cooperación internacional No. 112 de 2016. https://www.contratos.gov.co/ consultas/detalleProceso.do?numConstancia $=16-4-5476902$.

Agencia Nacional de Tierras y Oficina de Naciones Unidas contra la Droga y el Delito en Colombia. (2018b). Convenio de cooperación internacional No. 784 de 2018. https://www.contratos.gov.co/consultas/detalleProceso. do?numConstancia $=16-4-5476902$.

Asamblea Nacional Constituyente. (1991a). Gaceta Constitucional 5. https:// babel.banrepcultural.org/digital/collection/p17054coll28/search Asamblea Nacional Constituyente. (1991b). Gaceta Constitucional 50. https:// babel.banrepcultural.org/digital/collection/p17054coll28/search Asamblea Nacional Constituyente. (1991c). Gaceta Constitucional 82. https:// babel.banrepcultural.org/digital/collection/p17054coll28/search Asamblea Nacional Constituyente. (1991d). Gaceta Constitucional 107. https:// babel.banrepcultural.org/digital/collection/p17054coll28/search Asamblea Nacional Constituyente. (1991e). Gaceta Constitucional 123. https:// babel.banrepcultural.org/digital/collection/p17054coll28/search Asamblea Nacional Constituyente. (1991f). Gaceta Constitucional 136. https:// babel.banrepcultural.org/digital/collection/p17054coll28/search Álvarez Roa, P. (2012). Mercado de tierras: ¿acaparamiento o soberanía alimentaria? 
Berry, A. (2002). ¿Colombia encontró por fin una reforma agraria que funcione? Economía Institucional, 14(6), 24-70.

Banco Interamericano de Desarrollo. (1997) Programa de Titulación y Modernización del Registro y Catastro (CO0157).

Banco Interamericano de Desarrollo. (2014). Evaluación Comparativa: Proyectos de Regularización y Administración de Tierras. Anexo técnico 4.

Besley, T. (1995). Property Rights and Investment Incentives: Theory and Evidence from Ghana. Journal of Political Economy, 103(5), 903-937. https:// doi.org/10.1086/26200

Bruce, J. (2006). Introduction: Reforming land law to achieve development goals. En J. Bruce, R. Giovarelli, L. Rolfe Jr, D. Bledsoe, \& R. Mitchell, Land law reform achieving development policy objectives (pp. 1-9). The World Bank. http://hdl.handle.net/10986/7198

Centro Nacional de Memoria Histórica. (2013). La política de reforma agraria $y$ de tierras en Colombia: esbozo de una memoria institucional. https://www. centrodememoriahistorica.gov.co/descargas/informes2013/agraria/politicaagraria-tierras.pdf

Centro Nacional de Memoria Histórica (2016). Tierras y conflictos rurales. https://centrodememoriahistorica.gov.co/wp-content/uploads/2020/01/ tierras-y-conflictos-rurales.pdf

Colombia, Congreso de la República. Ley 200 de 1936, sobre régimen de tierras (30 diciembre 1936). http://www.suin-juriscol.gov.co/viewDocument.asp?ruta=Leyes $/ 1654991$

Colombia, Congreso de la República. Ley 135 de 1961, sobre reforma social agraria (15 diciembre 1961). http://www.suin.gov.co/viewDocument. asp?id=1792699

Colombia, Congreso de la República. Ley 160 de 1994, Por la cual se crea el Sistema Nacional de Reforma Agraria y Desarrollo Rural Campesino, se establece un subsidio para la adquisición de tierras, se reforma el Instituto Colombiano de la Reforma Agraria y se dictan otras disposiciones (3 agosto 1994). https://www.funcionpublica.gov.co/eva/gestornormativo/ norma.php?i=66789

Colombia, Congreso de la República. Ley 1579 de 2012, por la cual se expide el estatuto de registro de instrumentos públicos y se dictan otras disposiciones (1 octubre 2012). http://www.suin-juriscol.gov.co/viewDocument. asp?ruta $=$ Leyes $/ 1684387$

Colombia, Congreso de la República. (2019). ¿En qué va el acuerdo de paz a un año del gobierno de Duque? Retos y recomendaciones. https:// 
www.juanitaenelcongreso.com/post/en-que-va-el-acuerdo-de-paz-a-una\%C3\%Blo-del-gobierno-duque

Colombia, Corte Constitucional. Sentencia T-1037/02 (28 noviembre 2002). https://jurisprudenciaconstitucional.com/resolucion/101219-corte-constitucional-de-colombia-t-1037-02

Colombia, Corte Constitucional. Sentencia T-488/14 (9 julio 2014). https:// www.corteconstitucional.gov.co/RELATORIA/2014/T-488-14.htm

Colombia, Corte Constitucional. Sentencia T-567/17 (8 septiembre 2017). https://www.corteconstitucional.gov.co/relatoria/2017/t-567-17.htm

Colombia, Corte Suprema de Justicia. SC10882-2015 (18 agosto 2015). https:// www.redjurista.com/Documents/corte_suprema_de_justicia,_sala_de_casacion_civil_e._no._sc10882-2015_de_2015.aspx\#/

Colombia, Corte Suprema de Justicia. SC550-2020 (20 noviembre 2019). https:// cortesuprema.gov.co/corte/wp-content/uploads/2020/03/SC550-2020.pdf

Colombia, Corte Suprema de Justicia. STC3003-2020 (17 marzo 2020).

Colombia, Corte Suprema de Justicia. STL5308-2020 (5 agosto 2020).

Colombia, Presidencia de la República. Decreto 1250 de 1970, Por el cual se expide el estatuto del registro de instrumentos públicos (27 julio 1970). http://www.suin-juriscol.gov.co/viewDocument.asp?id=1737121

Colombia, Presidencia de la República. Decreto 902 de 2017, Por el cual se adoptan medidas para facilitar la implementación de la Reforma Rural Integral contemplada en el Acuerdo Final en materia de tierras, específicamente el procedimiento para el acceso y formalización y el Fondo de Tierras (29 mayo 2017). http://www.suin-juriscol.gov.co/viewDocument. asp?ruta $=$ Decretos $/ 30031898$

Colombia, Superintendencia de Notariado y Registro. Instrucción Administrativa 11 (30 julio 2015). https://www.supernotariado.gov.co/files/content/ instrucciones/2015/77986-INSTRUCCINADMINISTRATIVANo.11juli o30del2015.pdf

Colombia, Superintendencia de Notariado y Registro. Resolución 11885 de 2016 (27 octubre 2016). https://normograma.info/men/docs/pdf/resolucion_superregistro_11885_2016.pdf

Garzón, A., Ospina Hernández, M., Chalitas, M., Ossa Escobar, C., E Marulanda, I. (1991). Ponencia derechos agrarios. https://babel.banrepcultural. org/digital/collection/p17054coll28/search

Garzón, J. C., E Riveros, C. (2018). Acceso a la tierra y sustitución de cultivos ilícitos. Desafíos y oportunidades para el desarrollo rural. Notas Estratégicas (08). 
Gobernación de Antioquia y Oficina de Naciones Unidas contra la Droga y el Delito. (2010). Convenio de cofinanciación 2010.CF.18-51.

Güiza, D., Bautista, A.J., Malagón, A.M., E Uprimny, R. (2020). La constitución del campesinado: luchas por reconocimiento y redistribución en el campo jurídico. Dejusticia.

Machado (2009) Ensayos para la historia de la política de tierras en Colombia. De la colonia a Frente Nacional. CID, Universidad Nacional de Colombia.

Ministerio de Justicia y del Derecho de la República de Colombia \& Oficina de Naciones Unidas contra la Droga y el Delito. (2014). Modificación, adición y prórroga No. 1 al Convenio de cooperación No. 252 de 2013 entre el Ministerio de Justicia y del Derecho de la República de Colombia y la Oficina de Naciones Unidas contra la Droga y el Delito, proyectos COL/K53. https://www.contratos.gov.co/consultas/detalleProceso.do?numConstancia=17-4-6401580

Muñoz-Mora, J., Tobón, S., E D’Anjou, J. (2018). The Role of Land Property Rights in the War on Illicit Crops: Evidence from Colombia. World Development, 103, 268-283. https://doi.org/10.1016/j.worlddev.2017.10.021

Neva Díaz, J. (2014). Bases conceptuales. Procesos de regularización de la propiedad rural. Unidad de Planificación Rural Agropecuaria.

Oficina de Naciones Unidas contra la Droga y el Delito [UNODC]. (2017). XII Informe de avance técnico de la línea estratégica (a) formalización de tierras del Convenio 252 de 2013.

Peña Huertas, R., Parada Hernández, M. M., E Zuleta Ríos, S. (2014). La regulación agraria en Colombia o el eterno déjà vu hacia la concentración y el despojo: Un análisis de las normas jurídicas colombianas sobre el agro (1991-2010). Estudios socio-jurídicos, 16(1), 123-166.

Peña Huertas, R., E Zuleta Ríos, S. (2018). El Derecho al despojo en Colombia: un análisis de la regulación de adjudicación de baldíos desde abajo. Análisis Político, 31(92), 3-17. https://doi.org/10.15446/anpol.v31n92.71094 Peña Huertas, R., López Castro, Y., Valencia Herrera, M., Triana Ancinez, B., E Lozano Varcárcel, A. (2019). Sin zanahoria y con garrote: prevalencia del castigo en el diseño institucional de los programas de formalización para sustituir cultivos de uso ilícito en Colombia. Análisis Político, 32(97), 91-113. https://doi.org/10.15446/anpol.v32n97.87194

Peña Huertas, R. (2020). Covid19, campesinos y política pública; la necesidad de hacerse visible para acceder a la dotación de bienes públicos. En: X. Castro, D. Cagüeñas, D. P. Quintero, J. J. Fernández, E R. Silva (Ed.), Ensayos sobre la pandemia (pp. 209-218). Universidad ICESI. 
Procuraduría General de la Nación. (2020). Segundo informe al Congreso sobre el estado de avance de la implementación del Acuerdo de Paz.

Presidencia de la República. (1991a). Informe de la sesión de la comisión quinta del día 22 de abril de 1991. https://babel.banrepcultural.org/digital/collection/ p17054coll28/search

Presidencia de la República. (1991b). Informe de la sesión de la comisión quinta del día 19 de abril de 1991. https://babel.banrepcultural.org/digital/collection/ p17054coll28/search

Presidencia de la República. (1991c). Informe de la sesión de la comisión quinta del dia 24 de junio de 1991. https://babel.banrepcultural.org/digital/collection/ p17054coll28/search

Presidencia de la República. (1991d). Informe de la sesión de sesión plenaria del día 10 de junio de 1991. https://babel.banrepcultural.org/digital/collection/ p17054coll28/search

Reyes, A. (2016). La reforma rural para la paz. Debate.

Sánchez L., N.C. (2017). Tierra en transición. Justicia transicional, restitución de tierras y politica agraria en Colombia. Dejusticia.

de Soto, H. (2001). The mystery of capital: Why capitalism triumphs in the west and fails everywhere else. Black Swan.

Ubink, J. (2009). Legalising land rights in Africa, Asia and Latin America: An introduction. J. Ubink, A. Hoekema, \& W. Assies (Eds.), Legalising land rights. Local Practices, State Responses and Tenure Security in Africa, Asia and Latin America (pp. 7-32). Leiden University Press.

Verdad Abierta. (2020). ¿Rebelión de jueces permitió agilizar reforma agraria en Boyacá? https://verdadabierta.com/tras-los-baldios-de-la-nacion/rebelionde-jueces-permitio-agilizar-reforma-agraria-en-boyaca/

Villamil, C. (2015). La reforma agraria del Frente Nacional: De la concentración parcelaria de Jamundi al pacto de Chicoral. Utadeo.

USAID E ANT. (2018). Metodología para la formalización e individualización de predios en común y proindiviso. 